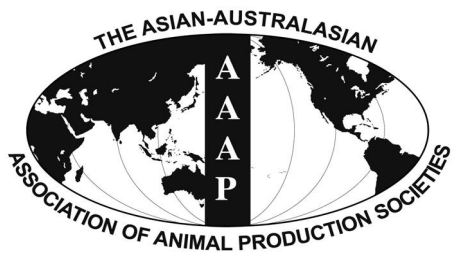

Open Access

Asian Australas. J. Anim. Sci.

Vol. 29, No. 10 : 1490-1499 October 2016

http://dx.doi.org/10.5713/ajas.15.0849

Www.ajas.info

pISSN 1011-2367 elSSN 1976-5517

\title{
Screening of Probiotic Activities of Lactobacilli Strains Isolated from Traditional Tibetan Qula, A Raw Yak Milk Cheese
}

\author{
Bei Zhang ${ }^{1,2}$, Yanping Wang ${ }^{1}$, Zhongfang Tan ${ }^{1, *}$, Zongwei Li ${ }^{1}$, Zhen Jiao ${ }^{1}$, and Qunce Huang ${ }^{1}$ \\ ${ }^{1}$ Henan Provincial Key Laboratory of Ion Beam Bio-engineering, \\ Zhengzhou University, Zhengzhou, Henan 450052, China
}

\begin{abstract}
In this study, 69 lactobacilli isolated from Tibetan Qula, a raw yak milk cheese, were screened for their potential use as

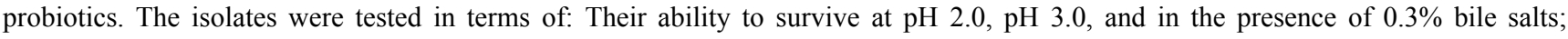
tolerance of simulated gastric and intestinal juices; antimicrobial activity; sensitivity against 11 specific antibiotics; and their cell surface hydrophobicity. The results show that out of the 69 strains, 29 strains (42\%) had survival rates above $90 \%$ after $2 \mathrm{~h}$ of incubation at $\mathrm{pH}$ values of 2.0 or 3.0. Of these 29 strains, 21 strains showed a tolerance for $0.3 \%$ bile salt. Incubation of these 21 isolates in simulated gastrointestinal fluid for $3 \mathrm{~h}$ revealed survival rates above $90 \%$; the survival rate for 20 of these isolates remained above $90 \%$ after $4 \mathrm{~h}$ of incubation in simulated intestinal fluid. The viable counts of bacteria after incubation in simulated gastric fluid for $3 \mathrm{~h}$ and simulated intestinal fluid for $4 \mathrm{~h}$ were both significantly different compared with the counts at $0 \mathrm{~h}(\mathrm{p}<0.001)$. Further screening performed on the above 20 isolates indicated that all 20 lactobacilli strains exhibited inhibitory activity against Micrococcus luteus ATCC 4698, Bacillus subtilis ATCC 6633, Listeria monocytogenes ATCC 19115, and Salmonella enterica ATCC 43971. Moreover, all of the strains were resistant to vancomycin and streptomycin. Of the 20 strains, three were resistant to all 11 elected antibiotics (ciprofloxacin, erythromycin, tetracycline, penicillin G, ampicillin, streptomycin, polymyxin B, vancomycin, chloramphenicol, rifampicin, and gentamicin) in this study, and five were sensitive to more than half of the antibiotics. Additionally, the cell surface hydrophobicity of seven of the 20 lactobacilli strains was above 70\%, including strains Lactobacillus casei 1,133 (92\%), Lactobacillus plantarum 1086-1 (82\%), Lactobacillus casei 1089 (81\%), Lactobacillus casei 1138 (79\%), Lactobacillus buchneri 1059 (78\%), Lactobacillus plantarum 1141 (75\%), and Lactobacillus plantarum 1197 (71\%). Together, these results suggest that these seven strains are good probiotic candidates, and that tolerance against bile acid, simulated gastric and intestinal juices, antimicrobial activity, antibiotic resistance, and cell surface hydrophobicity could be adopted for preliminary screening of potentially probiotic lactobacilli. (Key Words: Probiotic Activities, Screening, Lactobacilli, Qula Cheese)
\end{abstract}

\section{INTRODUCTION}

Probiotics are defined as living microorganisms that have beneficial effects on the host, and can adjust the host body's microecological balance, improve intestinal function, and stimulate digestion and immune function. Lactobacillus was the earliest discovered probiotic of the three types of probiotics, which also include Bifidobacterium and Gram-

* Corresponding Author: Zhongfang Tan. Tel: +86-371-677 61947, Fax: +86-371-67761947, E-mail: tzhongfang@zzu.edu.cn

2 Department of Chemical and Environmental Engineering, Jiaozuo University, Jiaozuo, Henan 454000, China.

Submitted Oct. 14, 2015; Revised Dec. 21, 2015; Accepted Jan. 14, 2016 positive cocci (Tulumoglu et al., 2013).

Lactobacillus is the largest genus of lactic acid bacteria (LAB), with 183 species, and are a group of rod-shaped or rod-like-shaped Gram-positive bacteria that can ferment glucose and produce lactic acid. Lactobacillus is the dominant bacteria in animal and human gastrointestinal and urinary systems, and plays an important role in the maintenance and recovery of health. Many species of Lactobacillus are recognized as safe for consumption, and thus, are often used in food production (de Almeida Júnior et al., 2015). Some species of Lactobacillus, including Lactobacillus acidophilus, Lactobacillus plantarum, Lactobacillus casei, Lactobacillus paracasei, Lactobacillus 
johnsonii, Lactobacillus reuteri, and Lactobacillus rhamnosus, have been used as probiotics (de Vos, 2011). In recent years, scientific research has confirmed the presence of large amounts of probiotic LAB in fermented dairy products and has shown their positive impact on human health. Qula is a white or yellow dried, hard, grainy cheese handcrafted from yak's milk in Tibet (Tan et al., 2010). Traditional Qula is fermented by microorganisms in the natural environment, and contains a large number of unique probiotic microorganisms, and to our knowledge, the isolation and screening of probiotic Lactobacillus from Qula has not been reported in the literature.

Increased attention has been paid to the probiotic abilities of Lactobacillus. Many factors need to be considered during the screening of potential probiotic LAB strains in vitro, including acid-bile salt tolerance; survival in gastric and intestinal fluids; their capability to adhere to intestinal surfaces; inhibition of pathogenic bacteria; and sensitivity to antibiotics.

The purpose of this study was to identify potential probiotic lactobacilli isolated from traditional handmade Qula cheese in the Qinghai province of China, and provide data for the development and utilization of probiotics.

\section{MATERIALS AND METHODS}

\section{Phenotypic and genotypic identification}

A total of 192 strains were isolated from traditional Tibetan Qula cheese based on colony morphology on de Man Rogosa Sharpe (MRS) agar (Tan et al., 2010). The isolates were initially identified based on their Gram reactions, catalase activity, gas production in the presence of glucose, and carbohydrate fermentation. The species were further identified based on 16SrRNA gene sequence analysis. Genomic DNA from each strain was first extracted using the Genomic DNA Mini Preparation Kit (Beyotime, Hangzhou, China), and amplification of the 16SrRNA gene was carried out in a thermal cycler using prokaryotic 16S ribosomal DNA universal primers: 27F (5'-AGAGTTTG ATCCTGGCTCAG-3') and 1492R (5'-GGTTACCTTGTTA CGACTT-3') (Tan et al., 2010). All sequences were then compared to those in the GenBank database using the BLAST program (http://blast.ncbi.nlm.nih.gov/Blast.cgi) (NCBI), resulting in the identification of 69 Lactobacillus isolates for the tests described below.

\section{Acid tolerance}

Acid tolerance was determined in accordance with the method by Chung et al. (1999), with slight modifications. In brief, $10 \mu \mathrm{L}$ of overnight bacterial culture in MRS broth

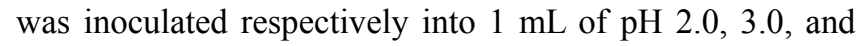
6.4 (control) MRS broth. The number of LAB was quantified using the plate count method on MRS agar after incubation at $37^{\circ} \mathrm{C}$ for $2 \mathrm{~h}$. The survival rate was calculated as log values of colony-forming units per milliliter (colonyforming unit $[\mathrm{CFU}] / \mathrm{mL}$ ).

\section{Bile salt tolerance}

Bile salt tolerance was determined according to the method by Gilliland et al. (1984). One percent overnight cultures in MRS broth were inoculated respectively into MRS broth with added $0.3 \%(\mathrm{w} / \mathrm{v})$ bile (test) and without bile (control). All samples were incubated in a $37^{\circ} \mathrm{C}$ water bath. Growth in the control (no bile) and test cultures $(0.3 \%$ bile) was determined by measuring the absorbance at 600 $\mathrm{nm}$ until the absorbance was increased by 0.3 units $(0.3 \mathrm{U})$. The difference (d) in the length of time between the two samples was considered to be the delay in growth due to inhibition by the bile salts.

\section{Simulation of tolerance to the gastrointestinal tract}

For the pancreatic fluid tolerance test, $0.35 \mathrm{~g}$ of pepsin and $100 \mathrm{~mL}$ of a $0.2 \%$ sterile $\mathrm{NaCl}$ solution were used at $\mathrm{pH}$ 2.5, as suggested by Charteris et al. (1998). To test tolerance to intestinal juice, in accordance with the method by Bao et al. (2010), $0.1 \mathrm{~g}$ of trypsin and $1.8 \mathrm{~g}$ of bile salts were added to a sterile solution of $1.1 \mathrm{~g}$ of $\mathrm{NaHCO}_{3}$ and $0.2 \mathrm{~g}$ of $\mathrm{NaCl}$ in $100 \mathrm{~mL}$ distilled water. The $\mathrm{pH}$ of the solution was adjusted to 8.0 with $0.5 \mathrm{M} \mathrm{NaOH}$. The simulated gastrointestinal fluid was sterilized by filtering through a $0.22 \mu \mathrm{m}$ membrane.

The lactobacilli for each test was incubated in MRS broth at $37^{\circ} \mathrm{C}$ for $24 \mathrm{~h}$. The cultures were then centrifuged for $5 \mathrm{~min}$ at $10,000 \mathrm{~g}$ and washed three times with $\mathrm{pH} 7.0$ phosphate-buffered saline (PBS) $\left(10^{8}\right.$ to $\left.10^{9} \mathrm{CFU} / \mathrm{mL}\right)$. A $10 \%$ solution of each sample was transferred into the simulated gastric and intestinal juices, respectively. Viability in the simulated gastric juice was counted at 0 and $3 \mathrm{~h}$ on MRS agar, and at 0 and $4 \mathrm{~h}$ in the simulated intestinal juice. The survival rate was calculated in the same manner as for the determination of the acid resistance.

\section{Antibacterial activity}

The inhibition of pathogenic bacteria was determined by the agar diffusion assay method (Ennahar et al., 2000) with Micrococcus luteus ATCC 4698, Bacillus subtilis ATCC 6633, Escherichia coli ATCC 11775, Listeria monocytogenes ATCC 19115, Staphylococcus aureus ATCC 29213, Salmonella enterica ATCC 43971, and Pseudomonas aeruginosa ATCC 27853 as the indicator strains. After being activated, each pathogen was suspended in sterile water and standardized to an absorbance of 1 at $600 \mathrm{~nm}$. The overnight lactobacilli cultures in MRS broth were centrifuged for $20 \mathrm{~min}$ at $10,000 \mathrm{~g}$, and the supernatants were filtered through a $0.22 \mu \mathrm{m}$ filter to remove residual cells. Twenty milliliters of MRS agar at $50^{\circ} \mathrm{C}$ were mixed 
with $200 \mathrm{~mL}$ overnight culture of the indicator strains and poured into a sterile plate. Wells $(7.80 \mathrm{~mm}$ in diameter) were made in the agar layer, and $300 \mu \mathrm{L}$ of cell-free supernatant was placed in each well. After incubation for 24 $\mathrm{h}$ at $37^{\circ} \mathrm{C}$, the diameters of the inhibition zones were measured.

\section{Sensitivity to antibiotics}

The sensitivity of the bacteria to antibiotics was determined by the agar overlay disc diffusion test (Charteris et al., 1998), using ciprofloxacin (CPFX; $5 \mu \mathrm{g}$ ), erythromycin $(15 \mu \mathrm{g})$, tetracycline $(30 \mu \mathrm{g})$, penicillin $\mathrm{G}(10$ $\mu \mathrm{g})$, ampicillin $(10 \mu \mathrm{g})$, streptomycin $(10 \mu \mathrm{g})$, polymyxin B $(300 \mu \mathrm{g})$, vancomycin $(30 \mu \mathrm{g})$, chloramphenicol $(30 \mu \mathrm{g})$, rifampicin $(5 \mu \mathrm{g})$, and gentamicin $(10 \mu \mathrm{g})$ antibiotic discs (Oxoid, Basingstoke, Hampshire, UK). Add $10 \mathrm{~mL}$ of MRS fluid nutrient medium to the sterile plate, and wait for it to solidify at room temperature. Add $5 \mathrm{~mL}$ MRS agar culturemedium $\left(50^{\circ} \mathrm{C}\right)$ into $250 \mu \mathrm{L}$ of overnight cultured Lactobacillus bacterial suspension $\left(10^{8} \mathrm{CFU} / \mathrm{mL}\right)$, mix them rapidly, and then pour the mixture into the plate with a base layer. Wait for the mixture to solidify, and then put drugsusceptible paper pasters on the medium with spaces of above $24 \mathrm{~mm}$. The inhibition zone diameters were measured after $24 \mathrm{~h}$ of incubation at $37^{\circ} \mathrm{C}$. The results were compared with breakpoint values designated by the Clinical and Laboratory Standards Institute (CLSI, 2012).

\section{Cell surface hydrophobicity}

Cell surface hydrophobicity was determined by the bacterial adhesion to hydrocarbons assay according to Rosenberg et al. (1980). The overnight bacterial culture in MRS broth was centrifuged at $10,000 \mathrm{~g}$ for $5 \mathrm{~min}$, and then equal volumes of the supernatant and PBS were mixed by vortexing for $30 \mathrm{~s}$. The absorbance of the mixture was measured at $600 \mathrm{~nm}\left(\mathrm{~A}_{0}\right)$. The PBS mixture was vortexed with dimethylbenzene for $60 \mathrm{~s}$ and incubated at $37^{\circ} \mathrm{C}$ for phase separation. The aqueous phase was gently removed, and its absorbance was measured at $600 \mathrm{~nm}\left(\mathrm{~A}_{\mathrm{t}}\right)$. The surface hydrophobicity $(\mathrm{H} \%)$ was calculated as follows:

$$
\mathrm{H} \%=\left(\mathrm{A}_{\mathrm{t}}-\mathrm{A}_{0}\right) / \mathrm{A}_{0} \times 100 \%
$$

\section{Statistical analysis}

Each assay was repeated on three independent occasions with triplicate determinations. Statistical analysis was performed using SPSS 13.0 software (SPSS, Inc., Chicago, IL, USA) with statistical significance determined at $\mathrm{p}<0.01$ or 0.05 . Results are expressed as the mean and standard error of the mean of three independent experiments. Oneway analysis of variance followed by Least significant difference test was used to determine significant differences of viability of the tested strains in simulated gastrointestinal fluid and also with respect to the cell surface hydrophobicity.

\section{RESULTS}

\section{Phenotypic and genotypic identification}

A total of 69 Gram-positive, catalase-negative, rodshaped isolates were acquired. The 69 strains used in this research were identified by a molecular method, and the isolates were characterized as Lactobacillus plantarum (34 strains), Lactobacillus casei (28 strains), Lactobacillus buchneri (3 strains), Lactobacillus diolivorans (1 strain), Lactobacillus sakei (1 strain), Lactobacillus curvatus (1 strain), and Lactobacillus kefiri (1 strain).

\section{Acid tolerance}

Sixty-nine Lactobacillus strains were examined for acid tolerance in this research. The acid tolerance of 29 isolates with good resistance to low $\mathrm{pH}$ are shown in Table 1. Additionally, Table 1 shows that the survival rates of 17 strains (Lactobacillus 70, 75, 1087, 1150, 1193-2, 1095, 1138, 1158, 1197, 1086-1, 1059, 32-2, 1156, 1033-1, 1089, 21 , and 1133) were $\geq 90 \%$ at $\mathrm{pH} \mathrm{3.0,} \mathrm{that} \mathrm{of} 21$ strains (Lactobacillus 1110, 1141, 49-1, 33, 1193-2, 1033-1, 30, 1134, 1150, 1138, 1158, 1035, 60, 1156, 1089, 1067, 1115, 1140,70 , and 1197) were $\geq 90 \%$ at $\mathrm{pH} 2.0$; nine of the 69 Lactobacillus strains (Lactobacillus 70, 1089, 1197, 1138, 1150, 1156, 1158, 1033-1, and 1093-2) showed good tolerance at both $\mathrm{pH} 2.0$ and 3.0. Strain 1133 was the most acid tolerant at $\mathrm{pH} 3.0$, with a survival rate of $97 \%$, and four strains (Lactobacillus 1067, 1115, 1140, and 70) were the most tolerant at $\mathrm{pH} 2.0$, with survival rates of $93 \%$. The viable counts of these 29 isolates in Table 1 all decreased at both pH 2.0 and 3.0 after $2 \mathrm{~h}$ compared with the control. The survival rates of 15 strains (Lactobacillus 30, 33, 60, 70, $1035,1059,1067,1110,1115,1134,1140,1141,1150,49-1$, and 1195-1) at $\mathrm{pH} 2.0$ were higher than at $\mathrm{pH}$ 3.0. Further screening was performed on these 29 strains as shown in Table 1.

\section{Bile tolerance}

Bile salts at a concentration of $0.3 \%$ had different degrees of inhibition on the 29 tested strains in this study. The results were analyzed using the standards suggested by Gilliland et al. (1984): resistant strains ( $d \leq 15 \mathrm{~min})$, tolerant strains $(15<\mathrm{d} \leq 40 \mathrm{~min})$, weakly tolerant strains $(40<\mathrm{d}<60$ $\mathrm{min})$, and sensitive strains ( $\mathrm{d} \geq 60 \mathrm{~min})$. Twenty-one $(72 \%)$ of the tested strains resisted $0.3 \%$ bile; their tolerances to bile are showed in Table 2. Two strains (Lactobacillus 75 and 1089) were considered to be resistant strains; six strains (Lactobacillus 21, 1067, 1138, 1141, 1193-2, and 1195-1) were tolerant strains; and 13 strains (Lactobacillus 1035, 1059, 1087, 1110, 1115, 1133, 1140, 1150, 1158, 1197, 32-2, 
Table 1. Viability $(\log \mathrm{CFU} / \mathrm{mL})$ and survival percentage of lactobacilli strains incubated at different $\mathrm{pH}$ values

\begin{tabular}{|c|c|c|c|c|c|}
\hline Strains & $\begin{array}{c}\mathrm{pH} 6.2^{1} \\
\text { Viable count } \\
(\log \mathrm{CFU} / \mathrm{mL})\end{array}$ & $\begin{array}{c}\text { pH } 3.0 \\
\text { Viable count } \\
(\log \text { CFU/mL) }\end{array}$ & $\begin{array}{c}\text { Percentage } \\
\text { survival (\%) }\end{array}$ & $\begin{array}{c}\mathrm{pH} 2.0 \\
\text { Viable count } \\
(\log \mathrm{CFU} / \mathrm{mL})\end{array}$ & $\begin{array}{c}\text { Percentage } \\
\text { survival (\%) }\end{array}$ \\
\hline L.buchneri 1158 & $8.91 \pm 0.28$ & $8.07 \pm 0.17$ & 91 & $8.08 \pm 0.30$ & 91 \\
\hline L.buchneri 1059 & $9.08 \pm 0.01$ & $8.36 \pm 0.14$ & 92 & $8.11 \pm 0.07$ & 89 \\
\hline L.casei 1067 & $8.90 \pm 0.16$ & $7.76 \pm 0.12$ & 87 & $8.29 \pm 0.09$ & 93 \\
\hline L.casei 1133 & $7.90 \pm 0.29$ & $7.67 \pm 0.06$ & 97 & $6.98 \pm 0.15$ & 88 \\
\hline L.casei 1138 & $9.09 \pm 0.06$ & $8.26 \pm 0.19$ & 91 & $8.26 \pm 0.03$ & 91 \\
\hline L.casei 1156 & $8.92 \pm 0.10$ & $8.28 \pm 0.21$ & 93 & $8.19 \pm 0.04$ & 92 \\
\hline L.casei32-2 & $8.39 \pm 0.07$ & $7.74 \pm 0.14$ & 92 & $7.29 \pm 0.09$ & 87 \\
\hline L.casei 1095 & $7.81 \pm 0.01$ & $7.11 \pm 0.02$ & 91 & $6.36 \pm 0.21$ & 81 \\
\hline L.casei 1035 & $8.75 \pm 0.02$ & $7.65 \pm 0.10$ & 87 & $8.08 \pm 0.04$ & 92 \\
\hline L.casei 1089 & $7.48 \pm 0.07$ & $7.09 \pm 0.23$ & 95 & $6.90 \pm 0.19$ & 92 \\
\hline L.casei 21 & $8.61 \pm 0.12$ & $8.29 \pm 0.17$ & 96 & $7.53 \pm 0.11$ & 87 \\
\hline L.casei30 & $8.67 \pm 0.07$ & $7.48 \pm 0.06$ & 86 & $7.90 \pm 0.02$ & 91 \\
\hline L.casei 70 & $8.97 \pm 0.02$ & $8.04 \pm 0.01$ & 90 & $8.31 \pm 0.06$ & 93 \\
\hline L.plantarum 1033-1 & $9.03 \pm 0.04$ & $8.45 \pm 0.02$ & 94 & $8.15 \pm 0.10$ & 90 \\
\hline L.plantarum $1086-1$ & $8.73 \pm 0.07$ & $7.98 \pm 0.13$ & 91 & $7.67 \pm 0.10$ & 88 \\
\hline L.plantarum 1087 & $8.96 \pm 0.08$ & $8.06 \pm 0.13$ & 90 & $7.75 \pm 0.02$ & 86 \\
\hline L.plantarum 1110 & $8.96 \pm 0.03$ & $7.76 \pm 0.16$ & 87 & $8.04 \pm 0.26$ & 90 \\
\hline L.plantarum 1115 & $8.78 \pm 0.11$ & $7.77 \pm 0.02$ & 88 & $8.16 \pm 0.06$ & 93 \\
\hline L.plantarum 1134 & $8.28 \pm 0.41$ & $7.26 \pm 0.13$ & 88 & $7.51 \pm 0.17$ & 91 \\
\hline L.plantarum 1140 & $9.06 \pm 0.03$ & $7.98 \pm 0.06$ & 88 & $8.45 \pm 0.05$ & 93 \\
\hline L.plantarum 1141 & $8.94 \pm 0.03$ & $7.90 \pm 0.05$ & 88 & $8.06 \pm 0.08$ & 90 \\
\hline L.plantarum 1150 & $8.96 \pm 0.26$ & $8.07 \pm 0.04$ & 90 & $8.16 \pm 0.05$ & 91 \\
\hline L.plantarum $1193-2$ & $8.77 \pm 0.21$ & $7.88 \pm 0.16$ & 90 & $7.90 \pm 0.09$ & 90 \\
\hline L.plantarum $1195-1$ & $8.85 \pm 0.14$ & $7.88 \pm 0.03$ & 89 & $8.13 \pm 0.08$ & 92 \\
\hline L.plantarum 1197 & $9.00 \pm 0.11$ & $8.15 \pm 0.16$ & 91 & $8.18 \pm 0.14$ & 91 \\
\hline L.plantarum 33 & $8.59 \pm 0.33$ & $7.65 \pm 0.10$ & 89 & $7.74 \pm 0.08$ & 90 \\
\hline L.plantarum49-1 & $8.45 \pm 0.18$ & $7.41 \pm 0.20$ & 88 & $7.57 \pm 0.13$ & 90 \\
\hline L.plantarum 60 & $8.55 \pm 0.09$ & $7.65 \pm 0.08$ & 89 & $7.90 \pm 0.17$ & 92 \\
\hline L.plantarum 75 & $8.75 \pm 0.23$ & $7.90 \pm 0.05$ & 90 & $7.73 \pm 0.19$ & 88 \\
\hline
\end{tabular}

CFU, colony-forming unit.

${ }^{1}$ Control. ${ }^{2}$ Percentage survival $=$ final $(\log \mathrm{CFU} / \mathrm{mL}) / \operatorname{control}(\log \mathrm{CFU} / \mathrm{mL}) \times 100 \%$.

1033-1, and 1086-1) were weakly tolerant strains.

\section{Tolerance to simulated gastric and intestinal juices}

The viability of 21 strains with good bile acid tolerance after exposure to simulated gastric and intestinal juices is shown in Figure 1 and 2. Compared with the conditions at 0 $\mathrm{h}$, the viable counts of bacteria after incubation in gastric fluid for $3 \mathrm{~h}$ and in intestinal fluid for $4 \mathrm{~h}$ were both significantly different $(\mathrm{p}<0.001)$. As shown in Figure 1, similar tolerances to simulated gastric juice were observed among the 21 strains tested; the viable counts for $3 \mathrm{~h}$ were all $1.00 \log \mathrm{CFU} / \mathrm{mL}$ less than those for $0 \mathrm{~h}$, with survival rates all $\geq 90 \%$. Strain 1133 had the highest survival rate $(95 \%)$ in gastric juice; its viable counts after $3 \mathrm{~h}$ were only $0.40 \log \mathrm{CFU} / \mathrm{mL}$ less than that for $0 \mathrm{~h}$. All strains (except strains 1035 and 1133) had better viability in simulated intestinal fluid for $4 \mathrm{~h}$ than in simulated gastric fluid for $3 \mathrm{~h}$.
Strains 1089 and 1138 had the highest survival rates (98\%) in intestinal juice.

\section{Antibacterial activity}

The assay of antimicrobial ability against seven pathogens was performed on the 20 lactobacilli strains that passed the biological barriers screening, and the results are shown in Table 3. All 20 strains exhibited inhibitory activity against $M$. luteus ATCC 4698 (with an inhibition zone 12.50 to $25.42 \mathrm{~mm}$ in diameter), B. subtilis ATCC 6633 (8.92 to $18.00 \mathrm{~mm}$ ), L. monocytogenes ATCC 19115 (11.00 to 22.14 $\mathrm{mm}$ ), and $S$. enterica ATCC 43971 (10.60 to $21.28 \mathrm{~mm}$ ). In addition, Lactobacillus strains 21, 75, 1067, 1087, 1089, $1110,1115,1138,1140,1141,1150,1033-1$, and 1193-2 exhibited antibacterial activity against all the pathogens used in this study; Lactobacillus strains 1133, 1158, 1197, 32-2, and 1195-1 inhibited all pathogens other than E. coli 
Table 2. Ability of lactobacilli strains to tolerate $0.3 \%(\mathrm{w} / \mathrm{v})$ bile (min)

\begin{tabular}{ccccc}
\hline Strains & I & II & III & IV \\
& $(\mathrm{d} \leq 15 \mathrm{~min})$ & $\begin{array}{c}(15<\mathrm{d} \\
\leq 40 \mathrm{~min})\end{array}$ & $\begin{array}{c}(40<\mathrm{d} \\
<60 \mathrm{~min})\end{array}$ & $(\mathrm{d} \geq 60 \mathrm{~min})$ \\
& & & &
\end{tabular}

\section{L.casei 21}

L.plantarum 75

L.casei 1035

L.buchneri 1059

L.casei 1067

L.plantarum 1087

L.casei 1089

L.plantarum 1110

L.plantarum 1115

L.casei 1133

L.casei 1138

L.plantarum 1140

L.plantarum 1141

L.plantarum 1150

L.buchneri 1158

L.plantarum 1197

L.casei32-2

L.plantarum $1033-1$

L.plantarum 1086-1

L.plantarum 1193-2

L.plantarum $1195-1$

I, group of bile-resistant strains; II, group of bile-tolerant strains; III, group of bile weakly tolerant strains; IV, group of bile-sensitive strains; +, member of the group (according to Gilliland et al., 1984).

(8.18 to $11.52 \mathrm{~mm}$ ); Lactobacillus 1086-1 inhibited all pathogens other than $S$. aureus (11.24 to $21.70 \mathrm{~mm}$ ); and Lactobacillus 1059 inhibited all pathogens other than $P$. aeruginosa (8.54 to $17.04 \mathrm{~mm}$ ). Further, Lactobacillus 1144 had the strongest inhibitory activity against $M$. luteus and $L$. monocytogenes; and Lactobacillus 1086-1, 1087, 1115, 1197 , and 1138 had the strongest inhibition against $B$. subtilis, E. coli, S. aureus, S. enterica, and P. aeruginosa, respectively. Most strains had weaker inhibition against $E$. coli than against the other pathogens.

\section{Antibiotic resistance}

The resistance of the 20 lactobacilli strains was tested against 11 antibiotics; the results are shown in Table 4. All the lactobacilli exhibited resistance to vancomycin and streptomycin. Fourteen lactobacilli $(70 \%)$ were sensitive to chloramphenicol, 11 lactobacilli $(55 \%)$ were sensitive to rifampin, 13 lactobacilli (65\%) were sensitive to ampicillin, 14 lactobacilli $(70 \%)$ were sensitive to tetracycline, 14 lactobacilli $(70 \%)$ were sensitive to erythromycin, 19 lactobacilli (95\%) were resistant to CPFX, 17 lactobacilli $(85 \%)$ were resistant to penicillin, 15 lactobacilli (75\%) were resistant to gentamicin, and 18 lactobacilli (90\%) were resistant to polymyxin B. Strains 32-2 and 1195-1 showed resistance against the 11 antibiotics used in the assay, and strains $21,1089,1110$, and 1138 were sensitive to more than half of the antibiotics.

\section{Cell surface hydrophobicity}

For further analysis of the cell surface characteristics, the cell surface hydrophobicity of the 20 lactobacilli were measured. As shown in Figure 3, the hydrophobicity of the different strains were significantly different $(p<0.05$; $\mathrm{p}<0.01$ ), and ranged from $15 \%$ to $92 \%$. The hydrophobicities of seven strains were more than 70\%: 1133 (92\%), 1086-1 (82\%), 1089 (81\%), 1138 (79\%), 1059 (78\%), 1141 (75\%), and $1197(71 \%)$.

\section{DISCUSSION}

In order to have probiotic effects in the intestinal tract, LAB must be capable of surviving passage through the gastrointestinal tract (GIT). Therefore, for probiotic LAB, resistance to the gastric acid environment is a prerequisite for survival and function in the intestinal tract. Depending on the specific individual's diet, the $\mathrm{pH}$ of the human gastric environment varies from 1.5 to 3.0 (Solieri et al., 2014), and is usually around 3. With the intake of foods such as dairy products, the gastric $\mathrm{pH}$ value rises to 3.0 or

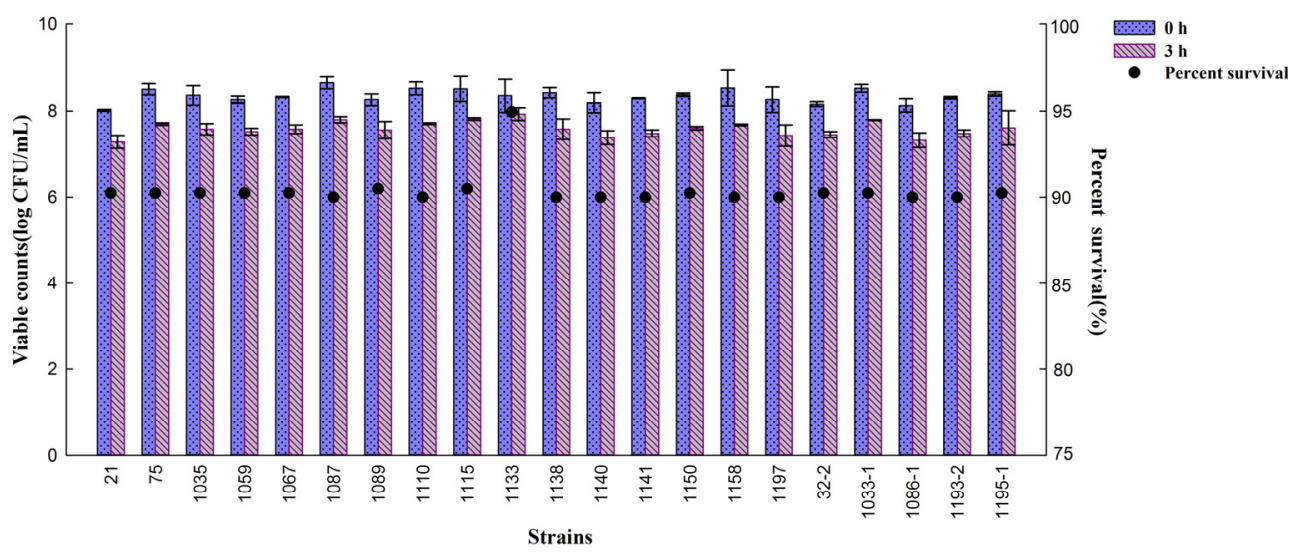

Figure 1. The viable counts $(\log \mathrm{CFU} / \mathrm{mL})$ and survival rates of lactobacilli strains after $3 \mathrm{~h}$ in the simulated gastric juice. 


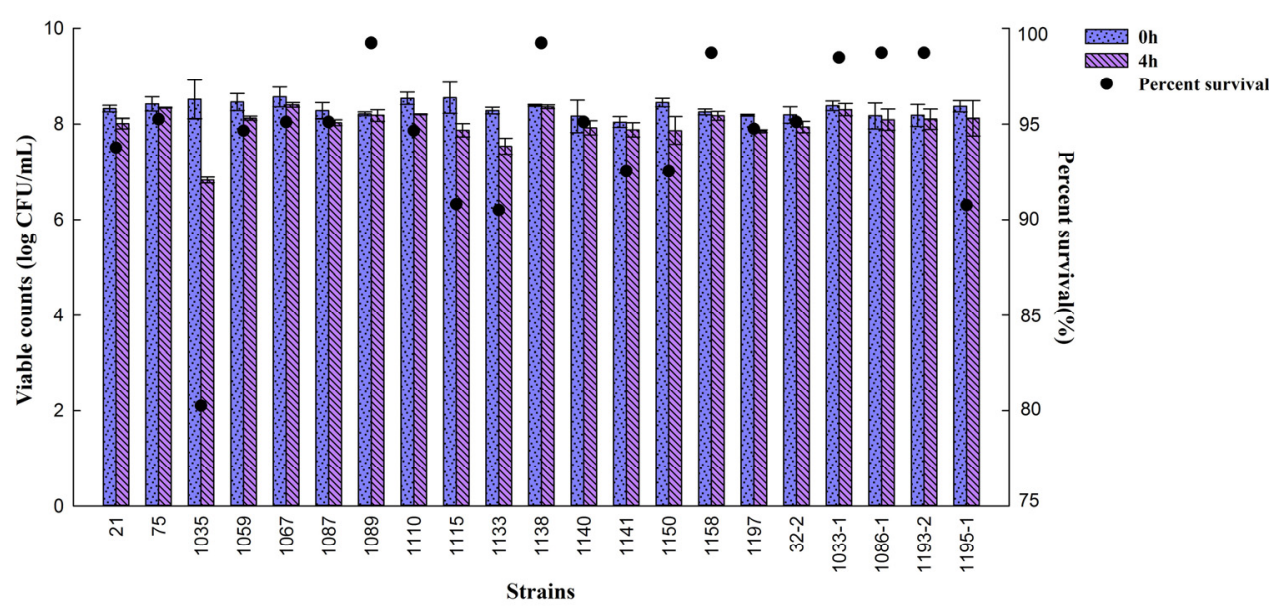

Figure 2. The viable counts $(\log \mathrm{CFU} / \mathrm{mL})$ and survival rates of lactobacilli strains after $4 \mathrm{~h}$ in the simulated intestinal juice.

even higher. In most studies, MRS broth with a $\mathrm{pH}$ value of 2.0 to 3.0 has been used to determine the acid resistance of Lactobacillus (Jacobsen et al., 1999; Tulumoglu et al., 2013; Solieri et al., 2014). Acid conditions have a large effect on the growth of Lactobacillus. In the present study, only 29 of the 69 isolates had survival rates $\geq 90 \%$ at conditions of $\mathrm{pH} 2.0$ or 3.0. At $\mathrm{pH} 3.0$, the percentage of tested strains with survival rates $\geq 90 \%$ was $25 \%$, which is lower than the percentage of $45 \%$ observed in a study by
Tulumoglu et al. (2013). In the present study, the percentage of strains with a favorable anti-acid performance at $\mathrm{pH} 2.0$ was $30 \%$. This percentage is better than that seen in a study by Mathara et al. (2008), who isolated Lactobacillus from traditional fermented dairy products made by the Maasai people in Kenya; strains with a favorable resistance at a $\mathrm{pH}$ of 2.0 accounted for $22.2 \%$ of the overall strains. In the Tulumoglu et al. (2013) study, the percentage of strains with a favorable resistance at $\mathrm{pH} 2.0$ was $25 \%$. Moreover, Solieri

Table 3. Antimicrobial activity of lactobacilli strains

\begin{tabular}{|c|c|c|c|c|c|c|c|}
\hline \multirow[b]{2}{*}{$\begin{array}{l}\text { Strains } \\
\qquad(\mathrm{a}=20)\end{array}$} & \multicolumn{7}{|c|}{ Antimicrobial activity } \\
\hline & $\begin{array}{c}\text { Micrococcus } \\
\text { luteus } \\
\text { ATCC } 4698\end{array}$ & $\begin{array}{l}\text { Bacillus subtilis } \\
\text { ATCC6633 }\end{array}$ & $\begin{array}{c}\text { Escherichia coli } \\
\text { ATCC } 11775\end{array}$ & $\begin{array}{c}\text { Listeria } \\
\text { monocytogenes } \\
\text { ATCC } 19115 \\
\end{array}$ & $\begin{array}{c}\text { Staphylococcus } \\
\text { aureus } \\
\text { ATCC29213 }\end{array}$ & $\begin{array}{c}\text { Salmonella } \\
\text { enterica } \\
\text { ATCC } 43971 \\
\end{array}$ & $\begin{array}{c}\text { Pseudomonas } \\
\text { aeruginosa } \\
\text { ATCC } 27853\end{array}$ \\
\hline $21(\mathrm{n}=7)$ & +++ & ++ & + & +++ & +++ & ++ & + \\
\hline $75(\mathrm{n}=7)$ & +++ & ++ & + & +++ & +++ & ++++ & + \\
\hline $1059(\mathrm{n}=6)$ & ++ & + & + & +++ & ++ & ++ & - \\
\hline $1067(\mathrm{n}=7)$ & ++++ & ++ & + & +++ & +++ & +++ & + \\
\hline $1087(\mathrm{n}=7)$ & ++++ & +++ & + & ++++ & + & ++++ & ++ \\
\hline $1089(\mathrm{n}=7)$ & +++ & + & + & +++ & ++++ & + & ++ \\
\hline $1110(\mathrm{n}=7)$ & ++++ & +++ & + & ++++ & +++ & +++ & + \\
\hline $1115(\mathrm{n}=7)$ & ++++ & +++ & + & +++ & ++++ & +++ & + \\
\hline $1133(\mathrm{n}=6)$ & ++ & + & - & +++ & + & ++ & ++ \\
\hline $1138(\mathrm{n}=7)$ & ++++ & ++ & + & ++++ & +++ & +++ & +++ \\
\hline $1140(\mathrm{n}=7)$ & ++++ & +++ & + & ++++ & +++ & ++++ & ++ \\
\hline $1141(\mathrm{n}=7)$ & ++++ & +++ & + & ++++ & ++++ & ++++ & ++ \\
\hline $1150(\mathrm{n}=7)$ & ++++ & +++ & + & ++++ & +++ & +++ & ++ \\
\hline $1158(\mathrm{n}=6)$ & ++ & + & - & ++ & ++ & ++ & ++ \\
\hline $1197(\mathrm{n}=6)$ & +++ & ++ & - & ++++ & +++ & ++++ & ++ \\
\hline $32-2(n=6)$ & ++ & + & - & + & ++ & ++ & + \\
\hline $1033-1(\mathrm{n}=7)$ & ++++ & ++ & + & ++++ & +++ & +++ & ++ \\
\hline $1193-2(n=7)$ & ++++ & +++ & + & ++++ & +++ & +++ & ++ \\
\hline $1195-1(\mathrm{n}=6)$ & ++ & ++ & - & +++ & +++ & ++++ & ++ \\
\hline $1086-1(\mathrm{n}=6)$ & ++++ & +++ & + & ++++ & - & +++ & ++ \\
\hline
\end{tabular}

+, Diameter of inhibition zone: 8.00 to $12.00 \mathrm{~mm}$; ++, 12.00 to $16.00 \mathrm{~mm}$; +++, 16.00 to $20.00 \mathrm{~mm}$; ++++, more than $20.00 \mathrm{~mm}$; -, not detected; the diameter of inhibition zone including that of Oxford cup $(7.80 \mathrm{~mm})$.

a, total number of lactobacilli strains. $n$, inhibition to number of pathogens. 
Table 4. Antibiotic susceptibility test of lactobacilli strains

\begin{tabular}{lccccccccccc}
\hline Strains & CHL & VA & GM & PB & RA & STR & AM ERY & CIP & PG & TE \\
\hline 21 & S & R & R & R & S & R & S & S & M & S & S \\
75 & S & R & M & R & S & R & S & S & R & R & S \\
1089 & S & R & S & S & S & R & S & S & R & S & S \\
1067 & S & R & R & R & S & R & S & S & R & R & S \\
1087 & S & R & R & R & M & R & S & M & R & R & S \\
1059 & S & R & R & R & M & R & R & S & R & R & S \\
$32-2$ & R & R & R & R & R & R & R & R & R & R & R \\
$1086-1$ & S & R & R & R & M & R & S & M & R & R & S \\
1110 & S & R & M & R & S & R & S & S & R & S & S \\
1115 & S & R & R & R & S & R & S & S & R & R & S \\
1133 & R & R & R & R & R & R & R & S & R & R & R \\
$1033-1$ & R & R & R & R & R & R & R & S & R & R & R \\
1140 & R & R & R & R & R & R & R & S & R & R & R \\
1141 & S & R & S & R & S & R & R & S & R & R & S \\
1150 & R & R & R & R & S & R & S & R & S & R & R \\
1158 & S & R & R & R & S & R & S & S & R & R & S \\
1197 & S & R & R & R & S & R & S & S & R & R & S \\
1138 & S & R & S & S & S & R & S & S & R & R & S \\
$1193-2$ & S & R & R & R & M & R & S & M & R & R & S \\
$1195-1$ & R & R & R & R & R & R & R & R & R & R & R \\
\hline
\end{tabular}

CH, chloramphenicol; VA, vancomycin; GM, gentamicin; PB, polymyxin B; RA, rifampin; STR, streptomycin; AM, ampicillin; ERY, erythromycin; CIP, ciprofloxacin; PG, penicillin; TE, tetracycline; R, resistant; $\mathrm{M}$, moderate resistance; $\mathrm{S}$, susceptible.

et al. (2014) found that almost none of the 47 Lactobacillus strains isolated from ripened Parmigiano-Reggiano cheese could survive conditions of $\mathrm{pH}$ 2.0. Furthermore, in a study by de Almeida Júnior et al. (2015), strains with favorable resistance at pH 2.0 only accounted for $72 \%$ of the 50 Lactobacillus strains isolated from ewe's milk. In the present study, the survival rates of strains with the best anti- acid performances were $97 \%$ and $93 \%$ at $\mathrm{pH}$ values of 3.0 and 2.0, respectively. Additionally, the visual CFU of some

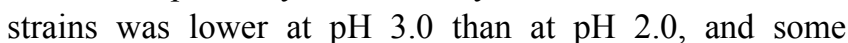
exhibited certain acidophilic properties, which may be due to the acidification process during Qula production. The results are similar to those from a study by Zhang (2011), who assessed the anti-acid performance of strains isolated from homemade traditional fermented yak's milk in the Gansu pasturing area, although these results were different from those of Tulumoglu et al. (2013). In the study by Tulumoglu et al. (2013), the visual CFU of all strains at high $\mathrm{pH}$ values was higher than those at low $\mathrm{pH}$ values.

Cholate damages the structure of cell membranes, leading to leakage of substances inside the cell, and making it difficult for thallus to survive. Therefore, a strain's tolerance to cholate is also of vital importance when assessing probiotic ability. The concentration of cholate inside healthy intestinal tracts varies from $0.03 \%$ to $0.30 \%$, and generally does not surpass $0.3 \%$ (w/v) (Gilliland et al., 1984), which is considered to be the critical concentration when screening for bile-tolerant strains (Gilliland et al., 1984; Jacobsen et al., 1999). Therefore, $0.3 \%$ bile was used in this study, and all strains tested showed growth delays in the $0.3 \%$ bile. Conversely, Jacobsen et al. (1999) found no growth delay in $0.3 \%$ bile for three strains isolated from Ghanaian fermented maize. In the present study, eight strains exhibited high levels of tolerance to bile (with delayed growth $\leq 40 \mathrm{~min}$ ). This result is superior to that of the Lactobacillus strains isolated from cow excrement in a study by Hyronimus et al. (2000), in which the growth delay for all studied strains were $>40 \mathrm{~min}$. The strains with the best tolerance in this study had growth delays of $<15$ min. This performance is superior to that from the study by Gilliland et al. (1984), in which the L. acidophilus strains

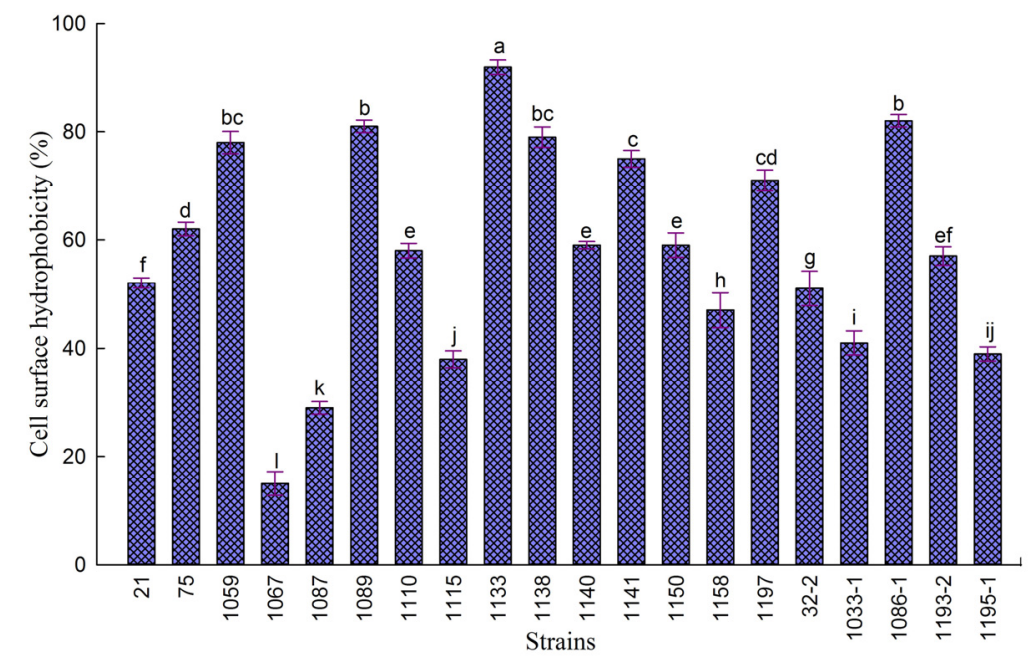

Figure 3. The surface hydrophobicity of selected lactobacilli strains as measured by their bacterial adherence to dimethylbenzene. $\mathrm{a}, \mathrm{b}, \mathrm{c}, \mathrm{d}, \mathrm{e}, \mathrm{f}, \mathrm{g}, \mathrm{h}, \mathrm{i}, \mathrm{j}, \mathrm{k}, \mathrm{l}$ Superscripts of the same letters indicate no significant inter-group differences, superscripts of different letters indicate significant inter-group differences $(p<0.05)$, and non-continuous letters indicate extremely significant inter-group difference ( $<<0.01)$. 
with the best tolerance, which were isolated from the fecal or intestinal contents of 2- to 5-week-old calves, showed growth delays of $20 \mathrm{~min}$.

The low $\mathrm{pH}$ of gastric juices and the gastric protease in gastric juices inhibit the growth of thallus. The small intestine is the major site of probiotic action, and various enzymes, bile acids, and other substances in small intestinal juice also inhibit probiotic growth. Therefore, GIT tolerance is an important criterion for the selection of potential probiotics. In the present study, during the GIT tolerance tests, almost all the strains exhibited better tolerance for simulated intestinal juice than simulated gastric juice. Further, Bao et al. (2010) reported that pancreatic fluid did not significantly affect LAB survival. In the present study, except for strain 1035, all the studied strains had survival rates $>90 \%$ in the simulated gastrointestinal fluid, with $<1.00 \log \mathrm{CFU} / \mathrm{mL}$ decreases in the viable counts. This result is superior to that of de Almeida Júnior et al. (2015). In a study by Prasad et al. (1998), significantly inferior results were found compared to those in the present study in terms of the simulated GIT tolerance of two commercial fermented strains, with decreases in the viable counts of $7.60 \log \mathrm{CFU} / \mathrm{mL}$. The results of the present study are similar to those of studies by Charteris et al. (1998) and Musikasang et al. (2009).

Probiotics can protect organisms via various mechanisms, including bacteriostasis, which plays the most important role in the determination of the dominant bacterial communities within intestinal ecological systems (Tulumoglu et al., 2013). In this study, 20 Lactobacillus strains showed different levels of inhibition against $M$. luteus, B. subtilis, S. aureus, L. monocytogenes, E. coli, $S$. enterica, and $P$. aeruginosa. The inhibition of Lactobacillus against these pathogenic bacteria had been reported in previous studies (Ammor et al., 2006; Tulumoglu et al., 2013; Asurmendi et al., 2015). Both Gram-positive and -negative bacteria were tested in the present study. Aymerich et al. (2000) reported that Gram-positive bacteria are more sensitive to Lactobacillus. Generally, although the 20 tested strains in this study could inhibit both Grampositive and -negative bacteria, showing a wide antimicrobial spectrum, they had the poorest inhibiting effect on E. coli.

Sensitivity to antibiotics is the most important factor in the safety evaluation of probiotics. Antibiotic resistance is a potential risk of probiotic application, as horizontal transfer of the antibiotic resistance gene has been demonstrated between lactobacilli and Enterococcus faecalis both in vivo (Ouoba et al., 2008) and in vitro (Jacobsen et al., 2007). Whether LAB can transfer tolerance to the pathogenic bacteria inside the intestinal tract is an important issue in the application of LAB. In the present study, $70 \%$ of the strains showed sensitivity to chloramphenicol, and LAB are usually sensitive to antibiotics such as chloramphenicol according to Klare et al. (2007). LAB isolated from wine by Rojo-Bezares et al. (2006) were all sensitive to chloramphenicol. In a study by Mathara et al. (2008), all 12 Lactobacillus strains isolated from kimchi were sensitive to chloramphenicol. Further, de Almeida Júnior et al. (2015) found that $96 \%$ of the studied strains were sensitive to chloramphenicol. Vancomycin was the first glycopeptide antibiotic applied clinically, and all the Lactobacillus strains in the present study showed tolerance for vancomycin, which is consistent with the results of Tulumoglu et al. (2013). According to Tulini et al. (2013), Lactobacillus has natural resistance against glycopeptide antibiotics such as vancomycin. In the study by de Almeida Júnior et al. (2015), $84 \%$ of the strains were sensitive to vancomycin, while Dasen et al. (2003) and Zhang (2011) found that all the Lactobacillus isolates tested were sensitive to vancomycin. These results do not support the statement of natural resistance against vancomycin in all Lactobacillus. Streptomycin and gentamicin both belong to the aminoglycoside antibiotic class, which strongly inhibits aerobic Gram-negative bacilli. In the present study, all the Lactobacillus strains showed resistance to streptomycin, while $75 \%$ of the strains were resistant to gentamicin; Tulumoglu et al. (2013) found that $90 \%$ of the Lactobacillus strains tested were resistant to gentamicin. These studies indicate weak inhibition of Lactobacillus by aminoglycoside antibiotics, which is consistent with the aforementioned statements. Only two strains in the present study showed sensitivity to polymyxin B; conversely, Zhang (2011) found that most of their tested strains were sensitive to polymyxin B. More than half of the Lactobacillus strains in the present study were sensitive to rifampicin, a rifamycin semisynthetic broad-spectrum antibiotic. This result was consistent with that of Zhang (2011). However, Essid et al. (2009) found that most of the 17 L. plantarum strains isolated from a Tunisian traditional salted meat showed resistance to rifampicin, which is not consistent with the results in the present study. In the present study, less than $50 \%$ of the strains showed tolerance for ampicillin, which is consistent with the results of Zhang (2011). However, Tulumoglu et al. (2013) found that all the studied strains were sensitive to ampicillin; further, Essid et al. (2009) observed that most strains showed tolerance for ampicillin, which is not consistent with the results in the present study. Additionally, most of the Lactobacillus strains in the present study were sensitive to erythrocin; likewise, all the Lactobacillus strains tested by Tulumoglu et al. (2013) and Mathara et al. (2008) showed sensitivity to erythrocin. The antibiotic CPFX belongs to the fluoroquinolone class of antibiotics, and some studies have reported that Lactobacillus has natural resistance against quinolones. In the present study, most of the strains (95\%) 
had tolerance for CPFX, compared to only $28 \%$ of the strains in the study by de Almeida Júnior et al. (2015). Penicillin antibiotics have been widely applied in clinical practice over a long period of time; therefore, tolerance for it is a widespread problem. In this study, only a small percentage (15\%) of the Lactobacillus strains were sensitive to penicillin, while all the strains studied by Tulumoglu et al. (2013), Mathara et al. (2008), and Zhang (2011) showed sensitivity to penicillin, which is inconsistent with the results from the present study. Tetracycline effectively inhibits both Gram-negative and -positive bacteria. In the present study, $70 \%$ of the Lactobacillus strains were sensitive to tetracycline. In the studies by Xanthopoulos et al. (2000) and Tulumoglu et al. (2013), all Lactobacillus strains isolated from infant feces were sensitive to tetracycline. However, Temmerman et al. (2003) and Essid et al. (2009) both found that most Lactobacillus strains show tolerance for tetracycline.

Surface properties vary for different Lactobacillus species, which can adhere to the intestinal mucosa via specific and nonspecific mechanisms. Cell hydrophobicity is a cell surface property that affects nonspecific adherence, and thus, can be used to evaluate the adherence ability of Lactobacillus. Lactobacillus isolated from the small intestine of swine was studied by Wadstroum et al. (1987) in terms of their ability to adhere to swine enterocytes; a positive correlation was found between the adherence ability and the surface hydrophobicity of Lactobacillus. The same conclusion was drawn by Holzapfel al. (1998). Many studies (Nostro et al., 2004; Solieri et al., 2014) have found that a hydrophobicity of above $70 \%$ is considered to be highly hydrophobic. In this study, a total of seven strains (35\%) had hydrophobicities above $70 \%$, indicating that some Lactobacillus strains isolated from traditional Tibetan Qula cheese had relatively high hydrophobicity. The highest hydrophobicity of the strains in this study was $92 \%$; similarly, the highest hydrophobicity found in the study by Zhang (2011) was 92.15\%.

In conclusion, seven Lactobacillus strains were selected as appropriate probiotic candidates in this study. Due to their probiotic properties tested, these strains might help to promote health of hosts, protect hosts from intestinal pathogens and maintain the natural balance of intestinal microflora during antibiotic treatments. However, additional studies are required to verify in vivo the effectiveness of selected strains.

\section{CONFLICT OF INTEREST}

We certify that there is no conflict of interest with any financial organization regarding the material discussed in the manuscript.

\section{ACKNOWLEDGMENTS}

This study was supported by the National Natural Science Foundation of China (No. 41101244); grants(Nos. 132300413205 and 152300410037) from Henan Province of China; and a grant from the Special Fund for AgroScientific Research in the Public Interest of China (No. 201103007).

\section{REFERENCES}

Ammor, S., G. Tauveron, E. Dufour, and I. Chevallier. 2006. Antibacterial activity of lactic acid bacteria against spoilage and pathogenic bacteria isolated from the same meat smallscale facility: 1-Screening and characterization of the antibacterial compounds. Food Control 17:454-461.

Asurmendi, P., M. J. García, L. Pascual, and L. Barberis. 2015. Biocontrol of Listeria monocytogenes by lactic acid bacteria isolated from brewer's grains used as feedstuff in Argentina. J. Stored Prod. Res. 61:27-31.

Aymerich, M. T., M. Garriga, J. M. Monfort, I. Nes, and M. Hugas. 2000. Bacteriocin-producing lactobacilli in Spanish-style fermented sausages: characterization of bacteriocins. Food Microbiol. 17:33-45.

Bao, Y., Y. Zhang, Y. Zhang, Y. Liu, S. Wang, X. Dong, Y. Wang, and H. Zhang. 2010. Screening of potential probiotic properties of Lactobacillus fermentum isolated from traditional dairy products. Food Control 21:695-701.

Charteris, W. P., P. M. Kelly, L. Morelli, and J. K. Collins. 1998. Antibiotic susceptibility of potentially probiotic Lactobacillus species. J. Food Prot. 61:1636-1643.

Charteris, W. P., P. M. Kelly, L. Morelli, and J. K. Collins. 1998. Development and application of an in vitro methodology to determine the transit tolerance of potentially probiotic Lactobacillus and Bifidobacterium species in the upper human gastrointestinal tract. J. Appl. Microbiol. 84:759-768.

Chung, H. S., Y. B. Kim, S. L. Chun, and G. E. Ji. 1999. Screening and selection of acid and bile resistant bifidobacteria. Int. J. Food Microbiol. 47:25-32.

CLSI (Clinical and Laboratory Standards Institute). 2012. Performance Standards for Antimicrobial Susceptibility Testing. 22nd edn. Clinical and Laboratory Standards Institute, Wayne, PA, USA.

Dasen, A., F. Berthier, R. Grappin, A. G. Williams, and J. Banks. 2003. Genotypic and phenotypic characterization of the dynamics of the lactic acid bacterial population of adjunctcontaining Cheddar cheese manufactured from raw and microfiltered pasteurized milk. J. Appl. Microbiol. 94:595-607.

de Almeida Júnior, W. L. G., Í. da Silva Ferrari, J. V. de Souza, C. D. A. da Silva, M. M. da Costa, and F. S. Dias. 2015. Characterization and evaluation of lactic acid bacteria isolated from goat milk. Food Control 53:96-103.

de Vos, W. M. 2011. Systems solutions by lactic acid bacteria: from paradigms to practice. Microb. Cell Fact. 10:S2

Essid, I., M. Medini, and M. Hassouna. 2009. Technological and safety properties of Lactobacillus plantarum strains isolated from a Tunisian traditional salted meat. Meat Sci. 81:203-208. 
Ennahar, S., T. Sashihara, K. Sonomoto, and A. Ishizaki. 2000. Class IIa bacteriocins: Biosynthesis, structure and activity. FEMS Microbiol. Rev. 24:85-106.

Gilliland, S. E., T. E. Staley, and L. J. Bush. 1984. Importance of bile tolerance of Lactobacillus acidophilus used as a dietary adjunct. J. Dairy Sci. 67:3045-3051.

Holzapfel, W. H., P. Haberer, J. Snel, and U. Schillinger. 1998. Overview of gut flora and probiotics. Int. J. Food Microbiol. 41:85-101.

Hyronimus, B., C. Le Marrec, A. H. Sassi, and A. Deschamps. 2000. Acid and bile tolerance of spore-forming lactic acid bacteria. Int. J. Food Microbiol. 61:193-197.

Jacobsen, C. N., V. Rosenfeldt Nielsen, A. E. Hayford, P. L. Moller, K. F. Michaelsen, A. Paerregaard, B. Sandstrom, M. Tvede, and M. Jakobsen. 1999. Screening of probiotic activities of forty-seven strains of Lactobacillus spp. by in vitro techniques and evaluation of the colonization ability of five selected strains in humans. Appl. Environ. Microbiol. 65:4949-4956.

Jacobsen, L., A. Wilcks, K. Hammer, G. Huys, D. Gevers, and S. R. Andersen. 2007. Horizontal transfer of tet(M) and erm(B) resistance plasmids from food strains of Lactobacillus plantarum to Enterococcus faecalis JH2-2 in the gastrointestinal tract of gnotobiotic rats. FEMS Microbiol. Ecol. 59:158-166.

Klare, I., C. Konstabel, G. Werner, G. Huys, V. Vankerckhoven, G. Kahlmeter, B. Hildebrandt, S. Muller-Bertling, W. Witte, and H. Goossens. 2007. Antimicrobial susceptibilities of Lactobacillus, Pediococcus and Lactococcus human isolates and cultures intended for probiotic or nutritional use. J. Antimicrob. Chemother. 59:900-912.

Mathara, J. M., U. Schillinger, P. M. Kutima, S. K. Mbugua, C. Guigas, C. Franz, and W. H. Holzapfel. 2008. Functional properties of Lactobacillus plantarum strains isolated from Maasai traditional fermented milk products in Kenya. Curr. Microbiol. 56:315-321.

Musikasang, H., A. Tani, A. H-kittikun, and S. Maneerat. 2009. Probiotic potential of lactic acid bacteria isolated from chicken gastrointestinal digestive tract. World J. Microbiol. Biotechnol. 25:1337-1345.

Nostro, A., M. A. Cannatelli, G. Crisafi, A. D. Musolino, F. Procopio, and V. Alonzo. 2004. Modifications of hydrophobicity, in vitro adherence and cellular aggregation of Streptococcus mutans by Helichrysum italicum extract. Lett. Appl. Microbiol. 38:423-427.
Ouoba, L. I. I., V. Lei, and L. B. Jensen. 2008. Resistance of potential probiotic lactic acid bacteria and bifidobacteria of African and European origin to antimicrobials: Determination and transferability of the resistance genes to other bacteria. Int. J. Food Microbiol. 121:217-224.

Prasad, J., H. Gill, J. Smart, and P. K. Gopal. 1998. Selection and characterisation of Lactobacillus and Bifidobacterium strains for use as probiotics. Int. Dairy. J. 8:993-1002.

Rojo-Bezares, B., Y. Sáenz, P. Poeta, M. Zarazaga, F. Ruiz-Larrea, and C. Torres. 2006. Assessment of antibiotic susceptibility within lactic acid bacteria strains isolated from wine. Int. J. Food Microbiol. 111:234-240.

Rosenberg, M., D. Gutnick, and E. Rosenberg. 1980. Adherence of bacteria to hydrocarbons: A simple method for measuring cellsurface hydrophobicity. FEMS Microbiol. Lett. 9:29-33.

Solieri, L., A. Bianchi, G. Mottolese, F. Lemmetti, and P. Giudici. 2014. Tailoring the probiotic potential of non-starter Lactobacillus strains from ripened Parmigiano Reggiano cheese by in vitro screening and principal component analysis. Food Microbiol. 38:240-249.

Tan, Z., H. Pang, Y. Duan, G. Qin, and Y. Cai. 2010. 16S ribosomal DNA analysis and characterization of lactic acid bacteria associated with traditional Tibetan Qula cheese made from yak milk. Anim. Sci. J. 81:706-713.

Temmerman, R., B. Pot, G. Huys, and J. Swings. 2003. Identification and antibiotic susceptibility of bacterial isolates from probiotic products. Int. J. Food Microbiol. 81:1-10.

Tulini, F. L., L. K. Winkelströter, and E. C. P. De Martinis. 2013. Identification and evaluation of the probiotic potential of Lactobacillus paraplantarum FT259, a bacteriocinogenic strain isolated from Brazilian semi-hard artisanal cheese. Anaerobe 22:57-63.

Tulumoglu, S., Z. N. Yuksekdag, Y. Beyatli, O. Simsek, B. Cinar, and E. Yaşar. 2013. Probiotic properties of lactobacilli species isolated from children's feces. Anaerobe 24:36-42.

Wadstroum, T., K. Andersson, M. Sydow, L. Axelsson, S. Lindgren, and B. Gullmar. 1987. Surface properties of lactobacilli isolated from the small intestine of pigs. J. Appl. Microbiol. 62:513-520.

Xanthopoulos, V., E. Litopoulou-Tzanetaki, and N. Tzanetakis. 2000. Characterization of Lactobacillus isolates from infant faeces as dietary adjuncts. Food Microbiol. 17:205-215.

Zhang, L. 2011. Evaluation of the Potential Probiotic Properties and Immune Regulation Function of Lactobacillus Strains Isolated from Traditional Fermented Yak Milk. Ph.D. Thesis, Gansu Agricultural University, Lanzhou, Gansu, China. 